\title{
Two-Dimensional Crystals from Reduced Symmetry Analogues of Trimesic Acid
}

\author{
Rachel A. Barnard, Ananya Dutta, Jennifer K. Schnobrich, Christine N. Morrison, \\ Seokhoon Ahn, and Adam J. Matzger*[a]
}

Abstract: The two-dimensional assembly of multicarboxylated arenes is explored at the liquid-graphite interface using scanning tunneling microscopy. Symmetry variations were introduced via phenylene spacer addition and the influence of these perturbations on the formation of hydrogen- bonded motifs from an alkanoic acid solvent is observed. This work demonstrates the importance of symmetry in 2D crystal formation and draws possible links of this behavior to prediction of coordination modes in three-dimensional coordination polymers.

\section{Introduction}

Long-range order in a layer of molecules assembled on a substrate can result in a two-dimensional (2D) crystal. In such 2D crystals, favorable molecule-molecule and molecule-substrate interactions can be incorporated at the stage of molecular design to promote long-range order during self-assembly. ${ }^{[1]}$ The number and type of available inter- and intramolecular interactions influence the pattern of the $2 \mathrm{D}$ crystal. As is the case in bulk crystallization, there is a drive towards close packing in monolayers to maximize intermolecular interactions. However, molecules that engage in directionally defined interactions are ideal for the formation of precisely ordered porous structures, and if the interactions are sufficiently strong these molecules are capable of overcoming close packed alternatives.

Trimesic acid (1,3,5-benzenetricarboxylic acid, TMA) is an archetypal, rigid, highly symmetric molecule offering three hydrogen-bonding moieties directionally favorable for the formation of ordered, nanoscale porous networks. The 2D self-assembly of TMA has been extensively studied in the literature at the solution/highly ordered pyrolytic graphite (HOPG) interface by STM. ${ }^{[2]}$ This study focuses on $2 \mathrm{D}$ crystals formed from analogues of TMA where molecular symmetry is reduced within the series by the addition of one or more phenylene spacers (Figure 1). This strategy for reducing molecular symmetry is expected to reduce the symmetry of the resultant $2 \mathrm{D}$ crystal due to the loss of two- and/or threefold symmetry within the series; the approach has met with success in $3 D$ crystal engineering of coordination polymers where the resul-

[a] Dr. R. A. Barnard, A. Dutta, Dr. J. K. Schnobrich, C. N. Morrison, Dr. S. Ahn, Prof. Dr. A. J. Matzger

Department of Chemistry and Macromolecular Science and Engineering University of Michigan, 930 N. University Dr, Ann Arbor, MI 48109 (USA) E-mail:matzger@umich.edu

Supporting information for this article is available on the WWW under http://dx.doi.org/10.1002/chem.201406332. tant reduction of network symmetry thwarts interpenetration. ${ }^{[3]}$ Therefore, the manifestation of symmetry reduction in controlling 2D assembly is of particular interest as a complexity-generating operation. During the structural investigation of various assemblies of the reduced symmetry analogues of TMA, six different phases were observed including four different plane groups and a disordered assembly. Similarities in the segregation of the distinct carboxylic acids in the cyclic hydrogen bonded dimers in 2D and carboxylates in related 3D coordination polymers are discussed. All imaging was conducted in an alkanoic acid solvent to solubilize these polar polycarboxylates. The role of solvent cannot be neglected in the assembly patterns, and this point is addressed below in the broader context.

\section{Results and Discussion}

The molecular design strategy employed in this study involves the asymmetrical addition of a phenylene spacer between the central benzene ring and one or more carboxylic acids of TMA or isophthalic acid. Isophthalic acid (1,3-benzenedicarboxylic acid, ISA) is a reduced symmetry analogue of TMA, due to the decrease in number of carboxylic acids from three to two. The first two asymmetrical variations in the structure of TMA are made by the addition of phenylene spacers in one direction, thus reducing the point group symmetry from $\sim D_{3 h}$ to $\sim C_{2 v}$ The assigned point group symmetries throughout this work treat carboxylic acids as carboxylates to be consistent with the resolution achievable in the STM images. The biphenyl analogue of TMA (1) and the terphenyl analogue 2 (Figure 1) both have a 1:2 ratio of symmetry inequivalent carboxylic acids. If two phenylene rings are added between the central aromatic ring and two carboxylic acid moieties of TMA, then molecule 3 is obtained which, like 1, 2, and ISA, displays $\sim C_{2 v}$ symmetry. Molecule $\mathbf{3}$ also has a 1:2 ratio of symmetry inequivalent carboxylic acids. The molecular symmetry of ISA is reduced to $\sim C_{s}$ by the insertion of a single phenylene ring between one car- 


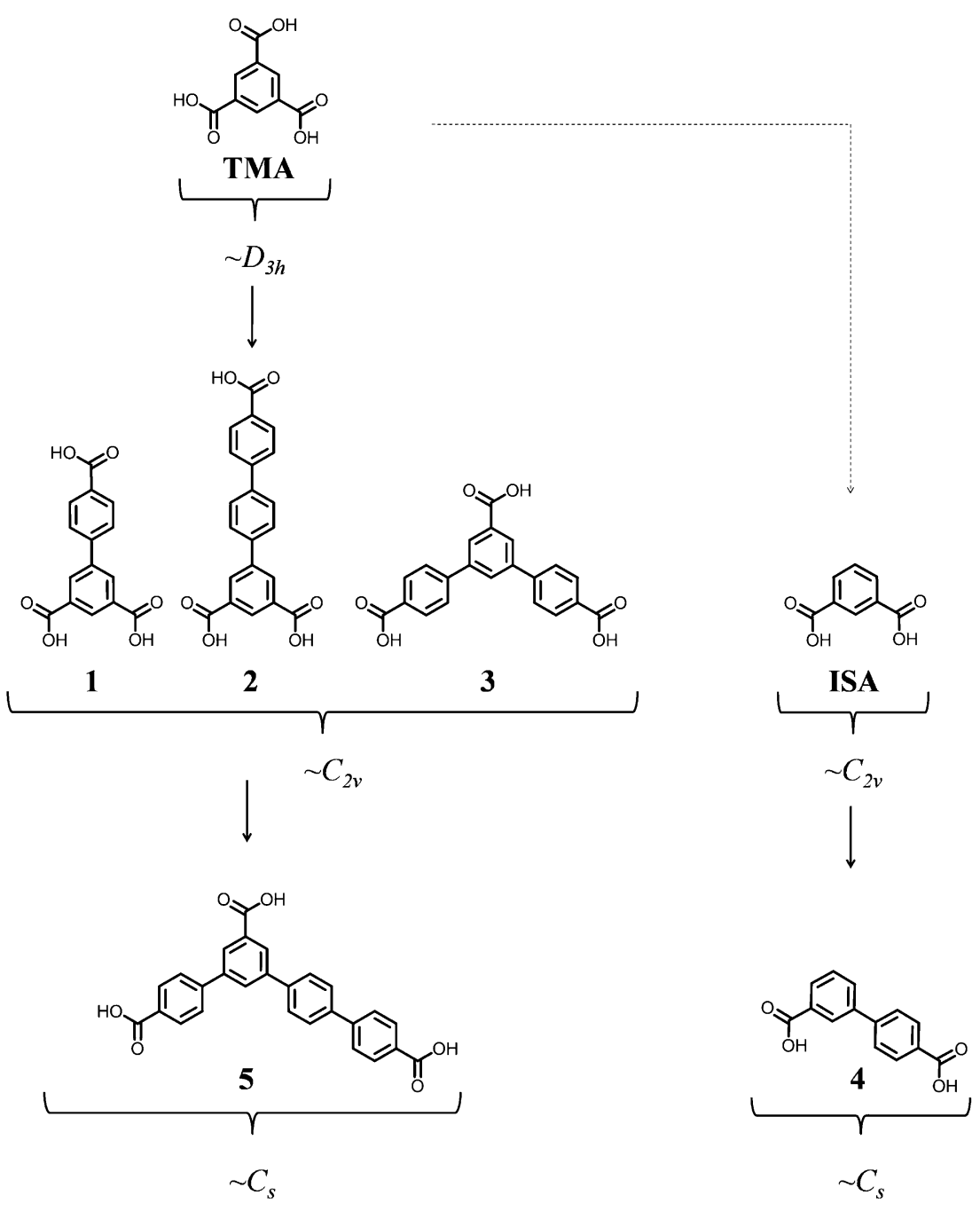

Figure 1. Molecular structures for the molecules investigated in this study. The dashed line represents a reduction in symmetry within the series by varying the number of carboxylic acid groups. The assigned point group symmetries treat carboxylic acids as carboxylates to be consistent with the resolution achievable in the STM images.

rates only hydrogen-bonded dimers of TMA. The flower phase resembles the chicken wire phase in that it has hexagonal pores with a TMA molecule at each vertex, but in the flower phase these hexagons are not fused together. Instead, they are slightly offset such that a hydrogen bond trimer is formed at each of the corners of the hexagon with TMA molecules from two other hexagon vertices. This hydrogen bonded trimer forms a threefold axis of rotation. A small pore is present between the edges of adjacent hexagons in the flower phase. Both the chicken wire and flower phases are in the $p 6$ plane group. A threefold axis of rotation lies on each TMA molecule in the chicken wire phase. However, in the flower phase, the threefold axis of rotation lies on the hydrogenbonded trimer, not on the TMA molecules themselves. A close packing phase of TMA has been demonstrated in dilute, solvophobic conditions. ${ }^{[12]}$ This phase forms with zig-zag lines of TMA molecules held together by hydrogen bonds between one carboxylic acid and the side of the dimers forming the zig-zag lines. This close packing phase is in the $p 2$ plane group. Due to

boxylic acid and the core benzene ring (4). Molecule 4 has a $1: 1$ ratio of symmetry inequivalent carboxylic acids. If a second phenylene spacer is added to molecule $\mathbf{3}$ between the central meta-substituted benzoic acid and one of the parasubstituted benzoic acids, molecule $\mathbf{5}$ is derived. Molecule $\mathbf{5}$ has $\sim C_{s}$ symmetry and a 1:1:1 ratio of symmetry inequivalent carboxylic acids. Using STM, the pattern of the self-assembled monolayer(s) that each molecule forms at the solution/HOPG interface was examined. The relationship between the point group of each molecule with respect to the symmetry of the assembled network(s) will be discussed for each phase. In some cases more than one phase was observed and therefore each is discussed separately.

The 2D crystals of TMA and ISA have been investigated in the literature at solution/HOPG interfaces. Computed models of the known phases for each molecule are shown in Figure 2. The "chicken wire" phase of TMA is a planar array of fused hexagons with a TMA molecule at each vertex. The hexagonal pores are $\sim 1 \mathrm{~nm}$ in diameter and have been shown to accommodate guest molecules. ${ }^{[4]}$ The chicken wire phase incorpo- the unique hydrogen bonding motif in the close packing phase, there are no threefold axes of rotation in that phase. ISA has one known phase: close packed ribbons of dimerized ISA molecules. ${ }^{[5]}$ This $2 \mathrm{D}$ crystal is in the $p 2 g g$ plane group. Structural features in the 2D crystals of the reduced symmetry analytes 1-5 from solution in $n$-heptanoic acid will be discussed in the context of the known phases of TMA and ISA.

\section{Molecule 1 Phase I}

Molecule 1 forms a phase consisting of columns of hydrogen bonded meta-meta dimers, shown in Figure 3. Due to the twofold symmetry from the hydrogen bonding of meta-meta dimers the apparent symmetry of this monolayer is $p 2$. Plane group $p 2$ is chiral, and the other enantiomer of this crystal is observed in separate domains; one such example is shown in Figure 3 c. Only homo-dimers are observed in the crystal. In other words, no cyclic hydrogen bonds are formed between meta- and para-substituted carboxylic acid moieties in this phase. The columns formed by dimers of $\mathbf{1}$ are separated by 


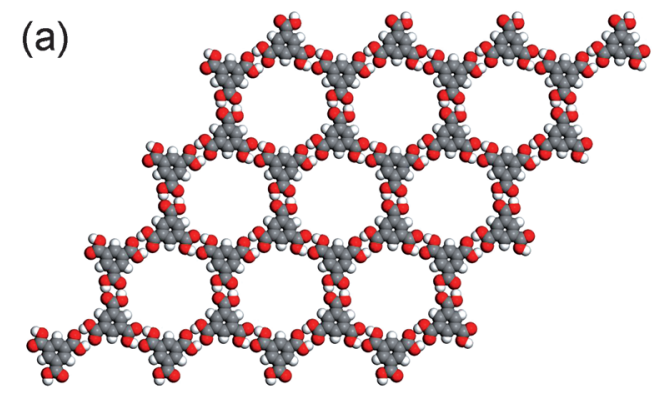

(c)

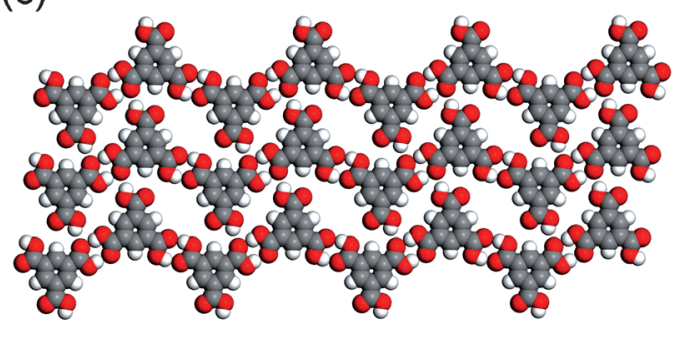

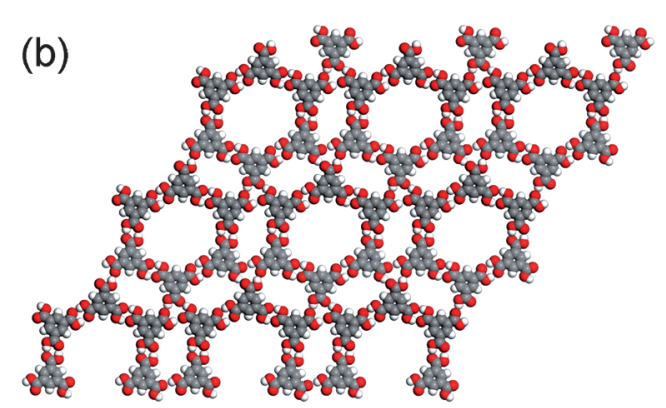

(d)

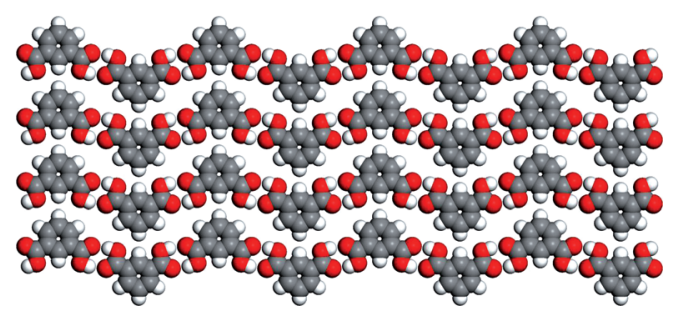

Figure 2. Computed models of a) the chicken wire phase of TMA, ${ }^{[2 b, c]}$ b) the flower phase of TMA, ${ }^{[2 b, c]}$ c) the close packing phase of TMA ${ }^{[2]]}$ and d) ISA $2 \mathrm{D} \mathrm{crys}^{-}$ tals ${ }^{[6 b]}$ based on literature STM studies at the solution/HOPG interface.
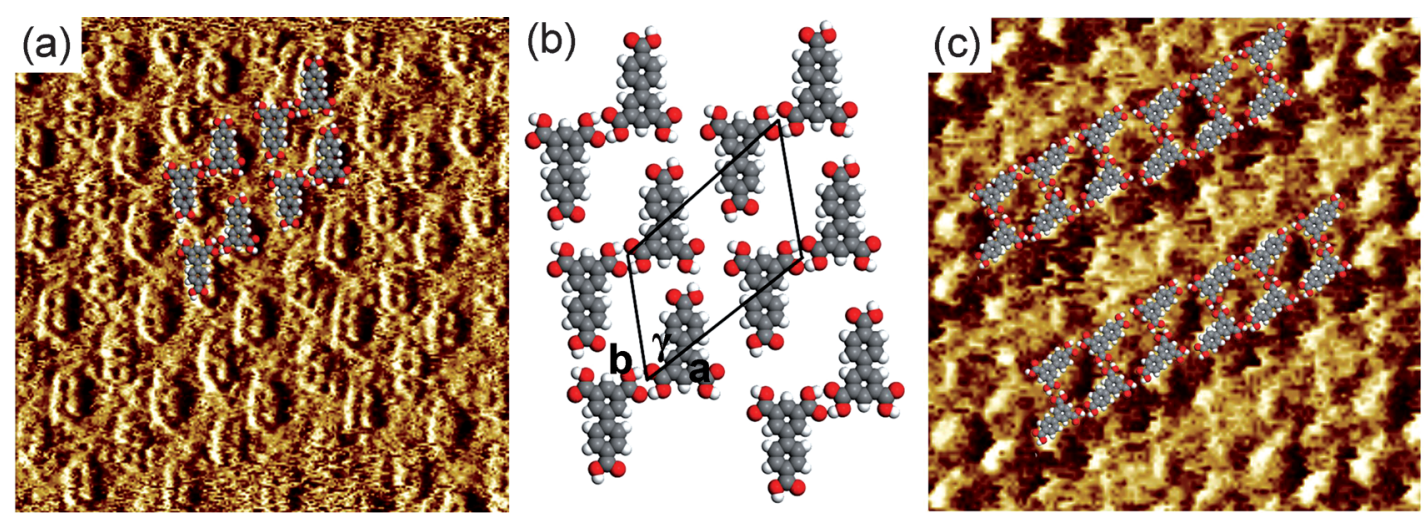

Figure 3. a) STM image $\left(10 \times 10 \mathrm{~nm}^{2}\right)$ of Phase I formed by molecule 1 in $n$-heptanoic acid with overlaid molecular model, b) computed model of the crystal structure of Phase I of 1 , and c) STM image $\left(10 \times 10 \mathrm{~nm}^{2}\right)$ of Phase I of molecule 1 formed in $n$-nonanoic acid.

$5.79 \pm 0.47 \AA$, a space too wide to allow for even weak hydrogen bonding between the columns. Using nonanoic acid as the solvent, a longer chain alkyl fatty acid solvent than heptanoic acid, the space between the columns of dimers increases (Figure 3c) giving rise to a more apparent disordered region between these columns and supporting the notion that solvent inclusion exists between columns of 1 dimers. ${ }^{[6]}$

\section{Molecule 1 Phase II}

Molecule 1 forms a zig-zag phase, shown in Figure 4, of repeating para-para and meta-meta hydrogen-bonding dimers. The "dangling" meta-substituted carboxylic acid is assumed to interact with the protic solvent in the space between the zigzag rows, similar to Phase I, and consistent with solvent incorporation. The length of the ribbon along the meta-meta dimer versus the para-para dimer results in an uneven herringbone- type pattern (Figure 4c). This 2D crystal has the apparent symmetry of $p 2$, with the twofold rotation axes at the center of each carboxylic acid homo-dimer. This phase is reminiscent of the ribbon phase of ISA (Figure $2 \mathrm{~d}$ ) but in this case the ribbons are slightly offset $\left(\gamma=83.5 \pm 4.27^{\circ}\right)$ and the length of interacting units along the ribbon axis differ.

While both Phase I and II of molecule 1 incorporate only homo dimers, Phase $I$ is built from meta-meta dimers and Phase II ribbons are composed of both meta-meta and parapara homodimers. Both phases are in the plane group $p 2$, but in Phase I four of the nine twofold rotation axes lie on the homo-dimers and six of the nine twofold rotation axes lie on the homo-dimers in Phase II. While the motifs differ in local arrangement, columns of dimers (Phase I) versus ribbons (Phase II), both phases incorporate only one unique molecule $\left(Z^{\prime}=1\right)$.

The carboxylate analogue of biphenyl tritopic linker 1 has been used to direct microporous coordination polymer (MCP) 


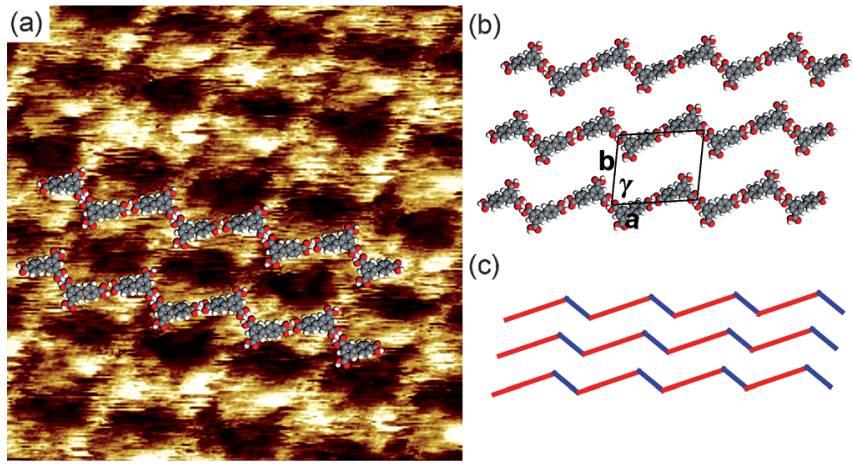

Figure 4. a) STM images $\left(10 \times 10 \mathrm{~nm}^{2}\right)$ of Phase II of 1 formed in heptanoic acid, b) computed model of the crystal structure of zig-zag pattern, and c) cartoon of the zig-zag phase highlighting the distorted herringbone pattern.

architecture. $^{[7]}$ It is the organic linker in the material UMCM$150,{ }^{[8]}$ the first material used to demonstrate reduced symmetry linkers as a route to preventing interpenetration in crystalline porous materials. ${ }^{[3]}$ In UMCM-150, the two symmetry inequivalent carboxylates segregate at the metal nodes: the isophthalate carboxylates form copper paddlewheels and the para-benzoates form the unusual copper cluster $\mathrm{Cu}_{3}\left(\mathrm{O}_{2} \mathrm{CR}\right)_{6}$ (see the Supporting Information). The 1:2 ratio of symmetry inequivalent carboxylates requires more than one type of copper cluster to be present in a given structure. ${ }^{[3]}$ In contrast, TMA has only symmetry equivalent carboxylate and HKUST-1, the MCP which incorporates the carboxylate version of TMA as the organic linker, has only one kind of copper cluster (see the Supporting Information). ${ }^{[9]}$ The consequence of the statistical requirement in UMCM-150 is that there are two kinds of copper clusters and the carboxylates segregate between them within the structure. ${ }^{[3]}$ In 2D assembly, and without the presence of a metal center, if all carboxylic acids are dimerized it is not possible to have a single mode of association for 1 because of the stoichiometric imbalance of para and meta substitutions. In fact, carboxylic acid segregation is present in the monolayers and all 1-1 interactions are homo dimers: meta-meta or para-para.

\section{Molecule 2}

The para-terphenyl derived tritopic linker, 2, forms a phase with small pores as shown in Figure 5 . The motif is formed by chains of repeating meta-meta dimers where the para-substituted carboxylic acids point in alternating directions along the $b$ axis of the crystal. The para-substituted carboxylic acids form homo-dimers linking the chains of meta-meta dimers and completing the elongated hexagonal pores $\left(2.85 \times 1.24 \mathrm{~nm}^{2}\right)$. This porous phase is an extended version of the chicken wire phase of TMA (Figure 2a). According to the molecular design strategy, molecule $\mathbf{2}$ is obtained when two phenylene rings are added between the central benzene ring and the same carboxylic acid of TMA (Figure 1). The added phenylene rings align with the $b$ axis in the crystal thus distorting the hexagonal chicken wire pores. With the loss of the threefold symmetry as compared to TMA, the monolayer also loses threefold symmetry features and lies in the rectangular plane group $\mathrm{cm}$. Molecule 2 has not been shown to form a MCP, and as such no comparisons can be drawn between 2D monolayer and 3D behavior.
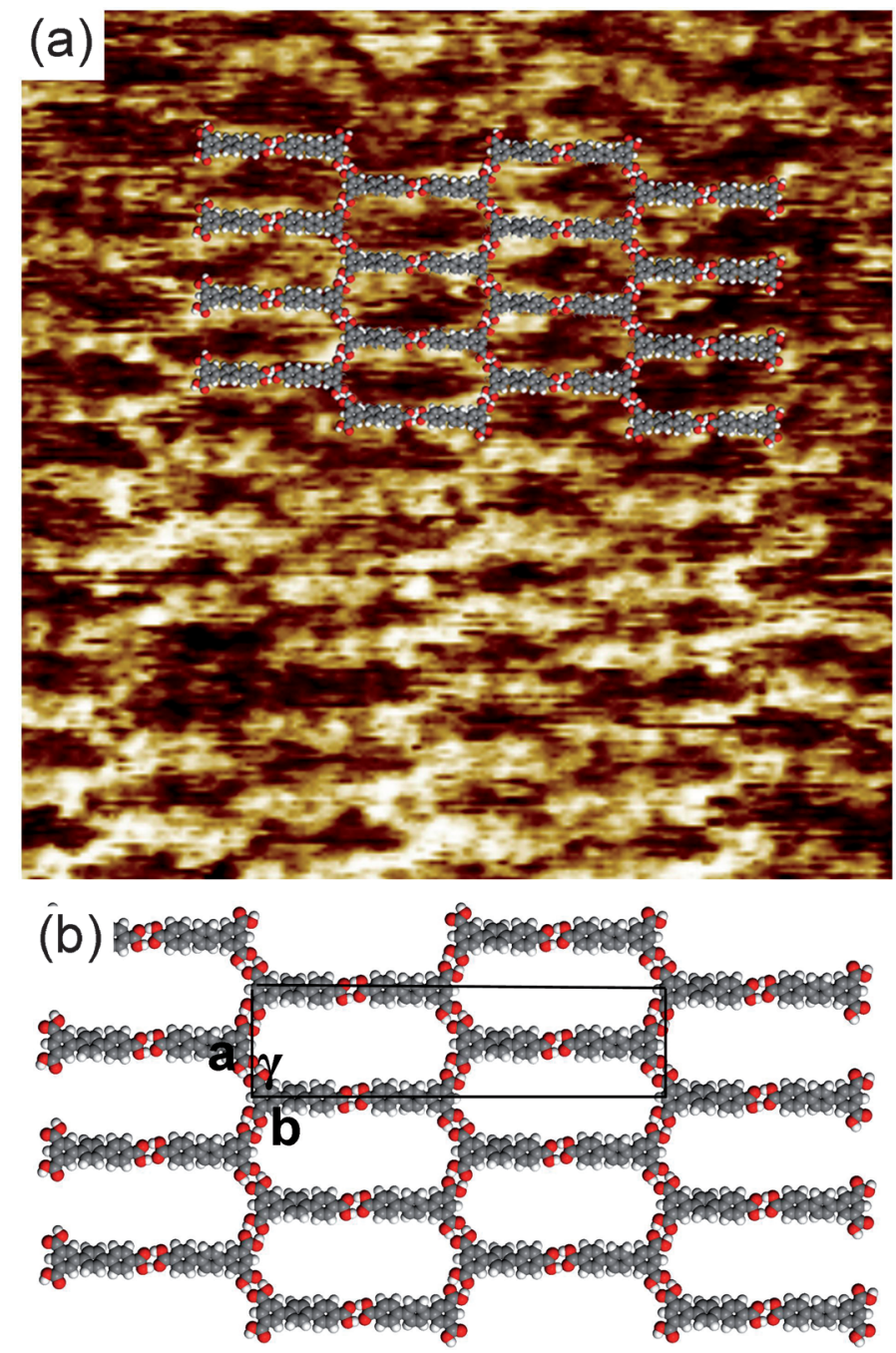

Figure 5. a) STM image $\left(20 \times 20 \mathrm{~nm}^{2}\right)$ of the monolayer 2 with overlaid model and b) the computed model of 2D crystal structure of $\mathbf{2}$.

\section{Molecule 3}

The meta-terphenyl tritopic linker, 3, forms a ribbon phase, shown in Figure 6. The 3-3 hydrogen-bond dimers are composed of trans-meta-meta cyclic dimers (Figure $6 \mathrm{~b}$ ). This phase is similar to that of ISA (Figure $2 \mathrm{~d}$ ) in that both have a $120^{\circ}$ angle between the trans-homo-dimers along a given ribbon, meaning that the other para-substituted carboxylic acids lie on opposite sides of the plane that contains the cyclic hydrogenbond dimer. Unlike Phase II of molecule 1, interacting units along the ribbon axis for each homo-dimer are of equal length. The apparent symmetry of this $2 \mathrm{D}$ crystal is $p 2 \mathrm{mg}$, a very uncommon plane group according to the $2 \mathrm{D}$ Structural Database ${ }^{\left[{ }^{[1 a]}\right]}$ there are only two other compounds in the database that have monolayers with $p 2 m g$ symmetry. ${ }^{[10]}$ 


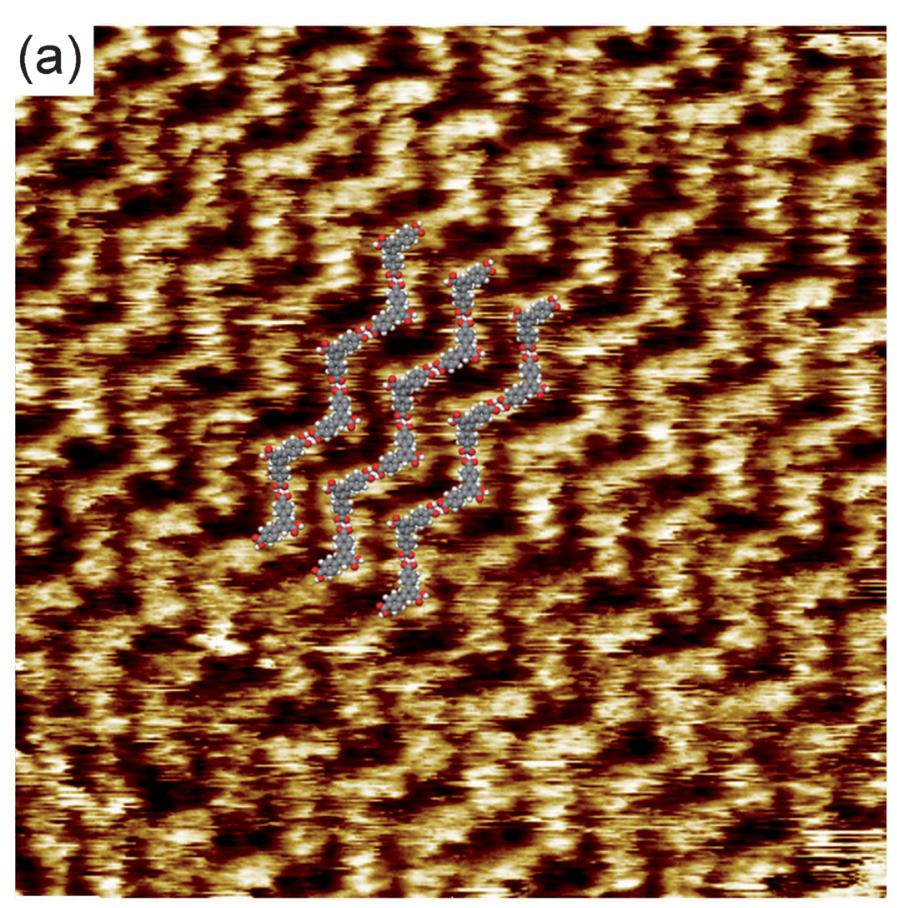

(b)

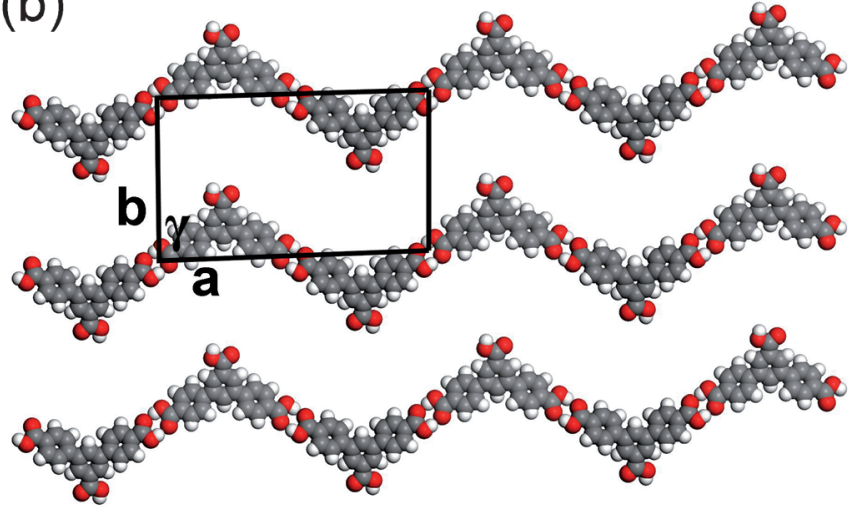

Figure 6. a) STM image $\left(25 \times 25 \mathrm{~nm}^{2}\right)$ of the monolayer 3 with overlaid model and b) the computed model of $2 \mathrm{D}$ crystal structure of 3 .

The carboxylate form of molecule $\mathbf{3}$ has been incorporated into the MCP UMCM-151, where the symmetry inequivalent carboxylates segregate such that each copper paddlewheel is coordinated by only para- or meta-substituted carboxylates (see the Supporting Information). ${ }^{[3]}$ To satisfy stoichiometry, there are two times as many para-coordinated paddlewheels as there are meta-coordinated paddlewheels. Similar to molecule $\mathbf{1}$, in the case of $\mathbf{3}$ the 1:2 ratio of symmetry inequivalent carboxylates requires more than one kind of paddlewheel coordination in the MCP structure.

\section{Molecule 4}

The phase formed by molecule $\mathbf{4}$ is a ribbon structure exclusively incorporating hetero dimers (Figure 7). With the metapara hydrogen bonds, the lack of twofold rotation axes, and an offset alignment of neighboring ribbons the $2 \mathrm{D}$ crystal is in the plane group $p 1$. This motif is built from two unique mole- cules $\left(Z^{\prime}=2\right)$ and as such is the only ordered phase in the series to incorporate more than one building block.

The carboxylate version of molecule $\mathbf{4}$ has been used as the organic linker in two isomeric MCPs. ${ }^{[11]}$ Both isomers are comprised of copper paddlewheels of two meta- and two para-carboxylates and vary in the coordination modes of the carboxylates at the paddlewheels. In one structure the carboxylate substitutions alternate around the $\mathrm{Cu}-\mathrm{Cu}$ axis in a meta-parameta-para arrangement. In the other isomer the sequence of carboxylate substitution around the $\mathrm{Cu}-\mathrm{Cu}$ axis is meta-metapara-para (see the Supporting Information). The lack of carboxylate segregation is possible due to the 1:1 ratio of symmetry inequivalent carboxylates in 4 . More than one kind of paddlewheel is not required in a given structure to satisfy the stoichiometry of the carboxylates. The 1:1 ratio of symmetry inequivalent moieties in 4 results in mixed copper paddlewheels in $3 \mathrm{D}$ and hetero-dimers in 2D.

\section{Molecule 5}

Tritopic quaterphenyl linker 5 has three symmetry inequivalent carboxylic acids. The primary monolayer motif formed by $\mathbf{5}$ has no regular, repeating pattern (Figure 8). In contrast to the examples of large scale disorder ${ }^{[12]}$ in the Two-Dimensional Structural Database (2DSD), ${ }^{[1]]}$ this assembly does not show areas of local order. Thermal annealing, dilution, and solvophobic conditions have been used in pursuit of obtaining an ordered phase for $\mathbf{5}$ and have thus far been unsuccessful.

The three carboxylic acids are symmetry inequivalent, resulting in at least 12 unique dimers that could be formed by molecule 5 in 2D. The availability of so many competing arrangements may contribute to the formation of the disorder ${ }^{[13]}$ at the solution/HOPG interface. Molecule $\mathbf{5}$ has not been shown to form a MCP, and as such no comparisons can be drawn between 2D monolayer and 3D behavior.

The monolayers formed from the five reduced symmetry analogues of TMA and ISA examined in this study show a strong dependence on the symmetry of the hydrogen-bonded dimer in determining the structure of the resulting $2 \mathrm{D}$ crystals. Table 1 summarizes the point group for the deprotonated structure of each molecule and the plane group for each monolayer based on the apparent symmetry in the image. The threefold axis of rotation in the apparent symmetry in monolayers of TMA was lost in monolayers assembled from molecules in this design strategy. Only one monolayer in this series does not incorporate homomeric hydrogen bonding (4) and that monolayer lies in the plane group $p 1$. Of the five ordered monolayers formed from this series, four different plane groups were observed. In contrast, the 2D crystals formed from reduced symmetry analogues of 1,3,5-benzenetribenzoic acid $\left(\mathrm{H}_{3} \mathrm{BTB}\right)$ all exhibited $p 2$ symmetry. ${ }^{[14]}$ From a molecular design perspective, TMA and ISA are the higher symmetry molecules that were used as the starting points for this route to a series of reduced symmetry multicarboxylated arenes through the addition of phenylene spacers (Figure 1). Both TMA and ISA have only symmetry equivalent carboxyl groups. 

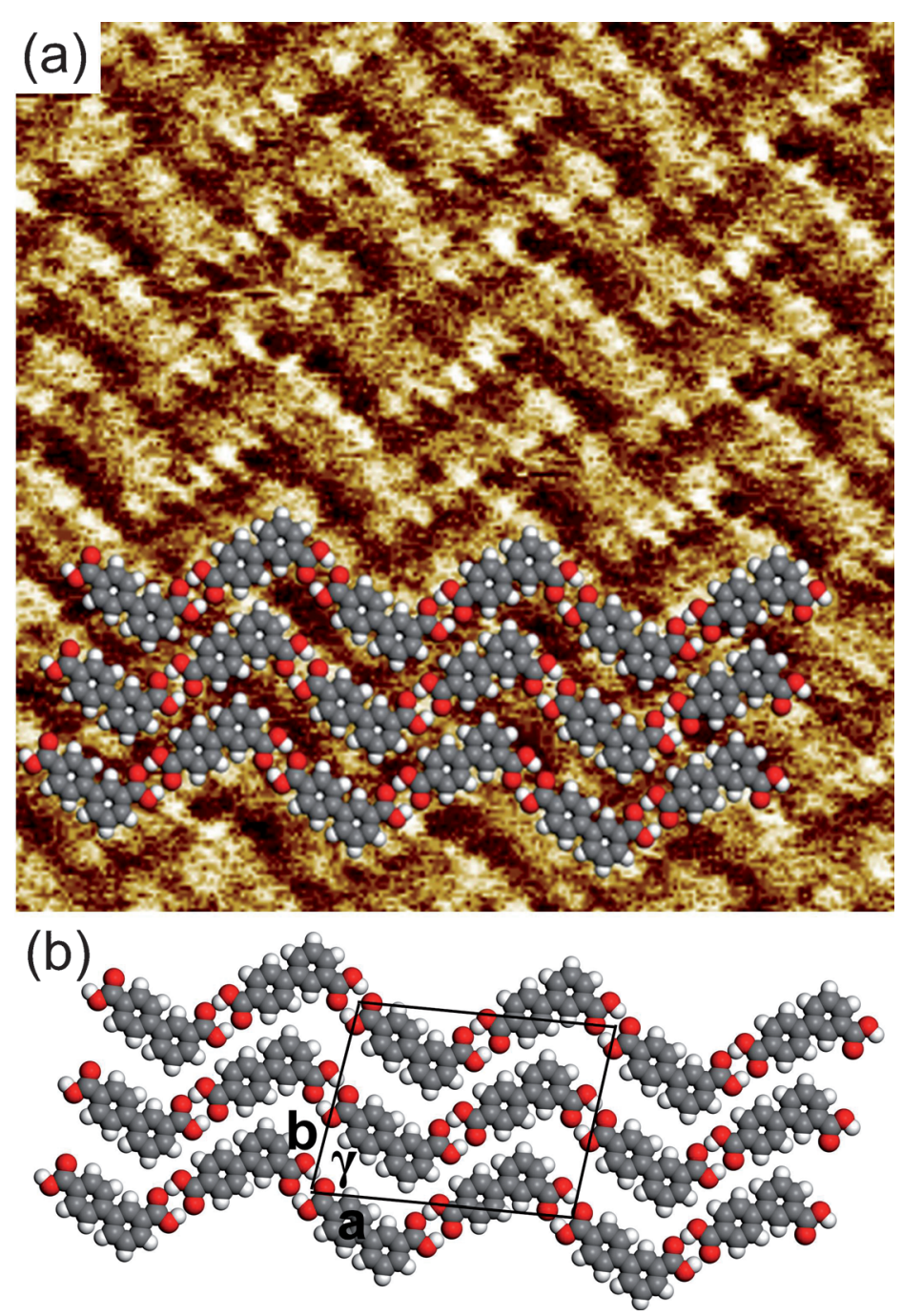

Figure 7. a) STM image $\left(10 \times 10 \mathrm{~nm}^{2}\right)$ of the monolayer of 4 with overlaid model and b) the computed model of 2D crystal structure of 4 .
For this series (Table 1), where there are only homo-dimers in 2D (molecules 1, 2, and 3), any symmetry inequivalent carboxylates are phase segregated in the 3D MCPs such that only one kind of carboxylate symmetry is present at each metal cluster. In the case of 4 , where hetero-dimers are formed in 2D, the metal centers in the MCP have a mixture of substituted carboxylates. There are no monolayers in this series with mixed hetero- and homo-dimers. In contrast, for a tetracarboxylate derivative of $\mathrm{H}_{3} \mathrm{BTB}$ (5'-(4carboxyphenyl)-[1,1':3', 1'"-terphenyl]-3,4", 5-tricarboxylic acid), both homo- and hetero-dimers are formed in $2 \mathrm{D}^{[14]}$ and the substitution of the carboxylates at each metal center in the two MPCs are mixed. ${ }^{[3]}$ This is, perhaps, not surprising in light of different geometry requirements to fill space in $2 \mathrm{D}$ and $3 \mathrm{D}$.

\section{Conclusion}

We have designed a series of five molecules related to TMA, an archetypal high symmetry adsorbate, through the addition of phenylene spacers. In contrast to monolayers formed from alternate routes to reduced symmetry adsorbates, self-assembly of molecules in this series yields six monolayers in five different plane groups. The composition of the cyclic carboxylic acid dimers (homo- or hetero-dimers) in the resultant $2 \mathrm{D}$ crystals at the liquid/HOPG interface is related to the stoichiometric ratio of symmetry inequivalent carboxylic acids of each analyte, and solvent inclusion is important for stabilizing carboxylic acids in the majority of the structures observed. Additionally, the analyte with a 1:1:1 ratio of symmetry inequivalent carboxylic acids (5) formed a disorderd phase at the solution/HOPG interface. The composition of the dimers in 2D (homo or hetero) mirrors the carboxylates composition (meta- or para-substituted) at the metal centers in MCPs incorporating these carboxylated arenes as the organic linkers. Such findings have design implications for using molecular symmetry to guide complex assemblies in both 2D and 3D.

\begin{tabular}{|c|c|c|c|c|}
\hline Name & Point group ${ }^{[a]}$ & Hydrogen-bonding interaction & Plane group & $Z^{\prime}$ \\
\hline \multirow[t]{3}{*}{ TMA } & \multirow[t]{3}{*}{$\sim D_{3 h}$} & homo-dimer & p6 & $1 / 3$ \\
\hline & & homo- \& hetero-dimer & p6 & 1 \\
\hline & & homo-dimer \& side & p2 & 1 \\
\hline \multirow[t]{2}{*}{1} & \multirow[t]{2}{*}{$\sim C_{2 v}$} & homo-dimer & $p 2$ & 1 \\
\hline & & homo-dimer & p2 & 1 \\
\hline 2 & $\sim C_{2 v}$ & homo-dimer & $\mathrm{cm}$ & 1 \\
\hline 3 & $\sim C_{2 v}$ & homo-dimer & $p 2 m g$ & $1 / 2$ \\
\hline ISA & $\sim C_{2 v}$ & homo-dimer & $p 2 g g$ & $1 / 2$ \\
\hline 4 & $\sim C_{s}$ & hetero-dimer & $p 1$ & 4 \\
\hline 5 & $\sim C_{s}$ & disorder & $\mathrm{n} / \mathrm{a}$ & $\mathrm{n} / \mathrm{a}$ \\
\hline
\end{tabular}

Figure 8. STM image $\left(25 \times 25 \mathrm{~nm}^{2}\right)$ of the monolayer of molecule 5 exhibiting disorder.

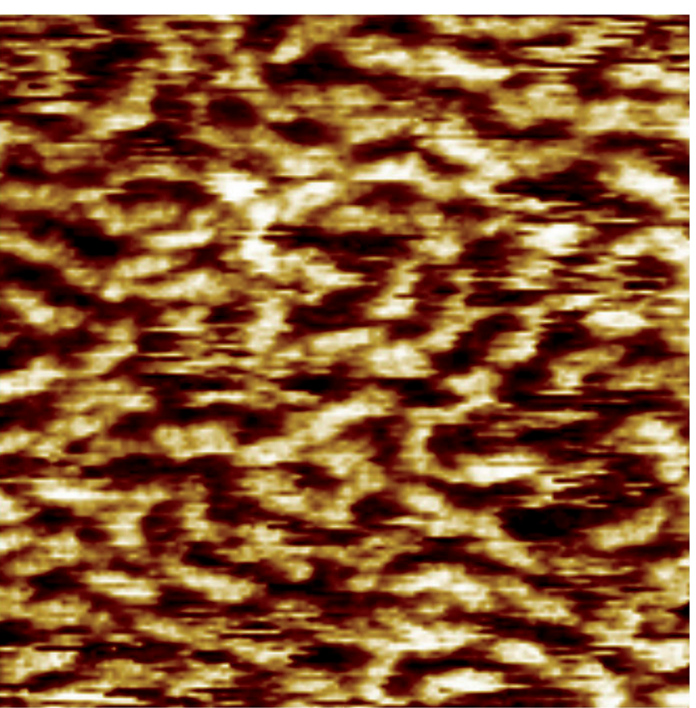

Chem. Eur. J. 2015, 21, 5954-5961

www.chemeurj.org 


\section{Experimental Section}

Materials: Compounds $\mathbf{1},{ }^{[15]} \mathbf{3}^{[8]}$ and $\mathbf{4}^{[11]}$ were synthesized according to literature methods. Heptanoic acid (98\%) was purchased from Acros Organics. The syntheses for $\mathbf{2}$ and $\mathbf{5}$ are described below.

3,4",5-Trimethyl-para-terphenyl: 4-Bromo-4'-methylbiphenyl $(1.56 \mathrm{~g}, 10.4 \mathrm{mmol}), 3,5$-dimethylphenylboronic acid $(2.00 \mathrm{~g}$, $9.43 \mathrm{mmol})$, toluene $(40 \mathrm{~mL}), \mathrm{EtOH}(30 \mathrm{~mL})$, and $2 \mathrm{M}$ aqueous $\mathrm{Na}_{2} \mathrm{CO}_{3}(30 \mathrm{~mL})$ were added into a pressure vessel equipped with a magnetic stir bar. The resulting mixture was sparged with $\mathrm{N}_{2}$ gas for $15 \mathrm{~min}$. $\mathrm{Pd}\left(\mathrm{PPh}_{3}\right)_{4}$ was added into the mixture, vessel was sealed, and the mixture was heated at $85^{\circ} \mathrm{C}$ for $18 \mathrm{~h}$. After cooling the reaction mixture to room temperature diethyl ether $(200 \mathrm{~mL})$ was added to the mixture. The organic and aqueous layers were separated, and the aqueous layer was extracted with diethyl ether $(3 \times 100 \mathrm{~mL})$. The organic layers were combined and dried over anhydrous $\mathrm{Na}_{2} \mathrm{SO}_{4}$. The organic layer was filtered and the solvent was removed under reduced pressure. The residue was recrystallized from a mixture of $\mathrm{CH}_{2} \mathrm{Cl}_{2} /$ hexane at $0{ }^{\circ} \mathrm{C}$ to produce a white solid $\left(1.73 \mathrm{~g}\right.$, yield 67.4\%). ${ }^{1} \mathrm{H} \mathrm{NMR}\left(500 \mathrm{MHz}, \mathrm{CDCl}_{3}\right): \delta=7.64(\mathrm{~s}, 4 \mathrm{H})$, $7.56(\mathrm{~d}, 2 \mathrm{H}, J=7.9 \mathrm{~Hz}), 7.28-7.26(\mathrm{~m}, 4 \mathrm{H}), 7.01(\mathrm{~s}, 1 \mathrm{H}), 2.41(\mathrm{~s}, 3 \mathrm{H})$, $2.39(\mathrm{~s}, 6 \mathrm{H}) ;{ }^{13} \mathrm{C}$ NMR $\left(125 \mathrm{MHz}, \mathrm{CDCl}_{3}\right): \delta=140.93,140.22,140.00$, $138.44,138.04,137.21,129.67,129.07,127.63,127.32,127.02$, $125.12,21.58,21.28$.

para-Terphenyl-3,4",5-tricarboxylic acid (2): 3,4",5-Trimethyl-paraterphenyl $(0.5 \mathrm{~g}, 1.8 \mathrm{mmol}), \mathrm{KMnO}_{4}(0.87 \mathrm{~g}, 5.5 \mathrm{mmol}), \mathrm{H}_{2} \mathrm{O}(20 \mathrm{~mL})$, and pyridine $(20 \mathrm{~mL})$ were added in a round bottom flask equipped with a magnetic stir bar and the mixture was heated to reflux for $3 \mathrm{~d}$. Additional aliquots of $\mathrm{KMnO}_{4}(8 \times 0.87 \mathrm{~g}, 5.5 \mathrm{mmol})$ were added during this period. After cooling the reaction mixture to room temperature the mixture was filtered over a plug of celite. The filtrate was evaporated and the residue was dissolved in water $(100 \mathrm{~mL})$. Insoluble solid was filtered off and the filtrate was acidified with concentrated $\mathrm{HCl}$. The white precipitate was collected by filtration, washed thoroughly with $\mathrm{H}_{2} \mathrm{O}$, and dried under vacuum to afford 2 (0.75 g, yield 64.6\%). ${ }^{1} \mathrm{H}$ NMR $\left(500 \mathrm{MHz},\left[\mathrm{D}_{6}\right] \mathrm{DMSO}\right): \delta=$ 13.39 (brs, $3 \mathrm{H}), 8.49(\mathrm{~s}, 1 \mathrm{H}), 8.42(\mathrm{~s}, 2 \mathrm{H}), 8.05(\mathrm{~d}, 2 \mathrm{H}, J=8.3 \mathrm{~Hz})$, 7.92-7.85 (m, 6H); ${ }^{13} \mathrm{C}$ NMR $\left(125 \mathrm{MHz},\left[\mathrm{D}_{6}\right] \mathrm{DMSO}\right): \delta=167.18$, $166.78,143.39,139.97,138.67,138.46,130.75,130.10,130.03$, $129.08,127.75,127.55,127.41,126.74 ;$ HRMS (EI): $\mathrm{m} / \mathrm{z}$ : calcd for $\mathrm{C}_{21} \mathrm{H}_{14} \mathrm{O}_{6}: 362.0790$; found: 362.0791 .

Methyl 4'-pinacolatoboronbiphenyl-4-carboxylate: Methyl 4'-bromobiphenyl-4-carboxylate $(2.50 \mathrm{~g}, 8.61 \mathrm{mmol})$, [bis-pinacolato]diboron $(2.62 \mathrm{~g}, 10.32 \mathrm{mmol}), \mathrm{KOAC}(2.50 \mathrm{~g}, 25.8 \mathrm{mmol})$, and 1,4-dioxane $(150 \mathrm{~mL})$ were added to a pressure vessel equipped with a magnetic stir bar. The resulting mixture was sparged for $1 \mathrm{~h}$ with $\mathrm{N}_{2}$ gas. $\mathrm{Pd}(\mathrm{dppf}) \mathrm{Cl}_{2}(0.21 \mathrm{~g}, 0.43 \mathrm{mmol})$ was added into the mixture, vessel was sealed, and the mixture was heated to reflux for $48 \mathrm{~h}$. After cooling the reaction mixture to room temperature the solvent was removed under reduced pressure. The residue was dissolved in $\mathrm{CH}_{2} \mathrm{Cl}_{2}(150 \mathrm{~mL})$ and washed with $\mathrm{H}_{2} \mathrm{O}(3 \times 100 \mathrm{~mL})$ followed by brine $(200 \mathrm{~mL})$. The organic layer was dried over anhydrous $\mathrm{MgSO}_{4}$, filtered, and the solvent was removed under reduced pressure. The crude product was subjected to gradient column chromatography (hexanes/ethyl acetate) to yield pure white solid ( $2.18 \mathrm{~g}$, yield $73.1 \%) .{ }^{1} \mathrm{H} \mathrm{NMR}\left(500 \mathrm{MHz}, \mathrm{CDCl}_{3}\right): \delta=8.12(\mathrm{~d}, 2 \mathrm{H}, J=$ $8.3 \mathrm{~Hz}), 7.90(\mathrm{~d}, 2 \mathrm{H}, J=8.2 \mathrm{~Hz}), 7.68(\mathrm{~d}, 2 \mathrm{H}, J=8.3 \mathrm{~Hz}), 7.64(\mathrm{~d}, 2 \mathrm{H}$, $J=8.2 \mathrm{~Hz}), 3.94(\mathrm{~s}, 3 \mathrm{H}), 1.37(\mathrm{~s}, 12 \mathrm{H}) ;{ }^{13} \mathrm{C} \mathrm{NMR}\left(125 \mathrm{MHz}, \mathrm{CDCl}_{3}\right)$ : $\delta=167.12,145.58,142.73,135.51,130.23,129.28,127.30,126.71$, $84.08,52.30,25.03$.

Dimethyl 5-bromobiphenyl-3,4'-dicarboxylate: Methyl 3,5-dibromobenzoate (15.0 g, $51.0 \mathrm{mmol})$, 4-(methoxycarbonyl)phenylboron- ic acid $(6.12 \mathrm{~g}, 34.0 \mathrm{mmol}), \mathrm{K}_{2} \mathrm{CO}_{3}(5.63 \mathrm{~g}, 40.8 \mathrm{mmol}), 200 \mathrm{~mL}$ 1,4dioxane, and $20 \mathrm{~mL} \mathrm{H} \mathrm{H}_{2} \mathrm{O}$ were added in a pressure vessel equipped with a magnetic stir bar. The resulting mixture was sparged for $1 \mathrm{~h}$ with $\mathrm{N}_{2}$ gas. $\mathrm{Pd}\left(\mathrm{PPh}_{3}\right)_{4}(2.01 \mathrm{~g}, 3.41 \mathrm{mmol})$ was added into the sparged mixture, vessel was sealed, and the mixture was heated to reflux for $48 \mathrm{~h}$. After cooling the reaction mixture to room temperature the solvent was removed under reduced pressure. The residue was dissolved in $\mathrm{CH}_{2} \mathrm{Cl}_{2}(200 \mathrm{~mL})$ and washed with $\mathrm{H}_{2} \mathrm{O}(3 \times$ $200 \mathrm{~mL}$ ) followed by brine $(300 \mathrm{~mL})$. The organic layer was dried over anhydrous $\mathrm{MgSO}_{4}$, filtered, and the solvent was removed under reduced pressure. The crude product was subjected to gradient column chromatography (hexanes/ethyl acetate) to yield pure white solid $(6.51 \mathrm{~g}$, yield $54.8 \%)$. ${ }^{1} \mathrm{H}$ NMR $\left(500 \mathrm{MHz}, \mathrm{CDCl}_{3}\right)$ : $\delta=8.22(\mathrm{t}, 1 \mathrm{H}, J=1.6 \mathrm{~Hz}), 8.19(\mathrm{t}, 1 \mathrm{H}, J=1.7 \mathrm{~Hz}), 8.16-8.11(\mathrm{~m}, 2 \mathrm{H})$, $7.94(t, 1 \mathrm{H}, J=1.84 \mathrm{~Hz}), 7.69-7.64(\mathrm{~m}, 2 \mathrm{H}), 3.96(\mathrm{~s}, 3 \mathrm{H}), 3.95(\mathrm{~s}, 3 \mathrm{H})$; ${ }^{13} \mathrm{C} \mathrm{NMR} \quad(125 \mathrm{MHz}, \mathrm{CDCl}): \delta=166.83,165.70,143.13,142.38$, $134.57,134.68,132.09,130.47,130.11,127.28,127.22,123.20,52.75$, 52.42 .

$\left[1,1^{\prime}: 3^{\prime}, 1^{\prime \prime}: 4^{\prime \prime}, 1^{\prime \prime \prime}\right.$-Quaterphenyl]-4,4"', $5^{\prime}$-tricarboxylic acid (5): Methyl 4'-pinacolatoboronbiphenyl-4-carboxylate $\quad(1.50 \mathrm{~g}$, $4.44 \mathrm{mmol})$, dimethyl 5-bromo-biphenyl-3,4'-dicarboxylate $(1.40 \mathrm{~g}$, $4.04 \mathrm{mmol}), \mathrm{K}_{2} \mathrm{CO}_{3}(1.95 \mathrm{~g}, 14.1 \mathrm{mmol}), \mathrm{THF}(70 \mathrm{~mL})$, and $\mathrm{H}_{2} \mathrm{O}$ $(10 \mathrm{~mL})$ were added in a pressure vessel equipped with a magnetic stir bar. The resulting mixture was sparged for $1 \mathrm{~h}$ with $\mathrm{N}_{2}$ gas. $\mathrm{Pd}\left(\mathrm{PPh}_{3}\right)_{4}(0.465 \mathrm{~g}, 0.403 \mathrm{mmol})$ was added to the mixture, vessel was sealed, and the mixture was heated to reflux for $48 \mathrm{~h}$. After cooling the reaction mixture to room temperature the solvent was removed under reduced pressure. The residue was dissolved in $\mathrm{CH}_{2} \mathrm{Cl}_{2}(150 \mathrm{~mL})$ and washed with $\mathrm{H}_{2} \mathrm{O}(3 \times 100 \mathrm{~mL})$ followed by brine $(200 \mathrm{~mL})$. The organic layer was dried over anhydrous $\mathrm{MgSO}_{4}$, filtered, and the solvent was removed under reduced pressure. The crude product was subjected to gradient column chromatography (hexanes/ethyl acetate) to yield pure white solid. This white solid $(1.31 \mathrm{~g}, 2.73 \mathrm{mmol}), 1$, -dioxane $(40 \mathrm{~mL}), \mathrm{H}_{2} \mathrm{O}(40 \mathrm{~mL})$, and $\mathrm{KOH}$ $(1.53 \mathrm{~g}, 27.3 \mathrm{mmol})$ were added into a pressure vessel equipped with a magnetic stir bar. The resultant suspension was heated to reflux for $12 \mathrm{~h}$. After cooling to room temperature the reaction mixture was filtered and the solvent was removed under reduced pressure. The residue was dissolved in $\mathrm{H}_{2} \mathrm{O}(200 \mathrm{~mL})$ and the solution was acidified with concentrated $\mathrm{HCl}$ until the $\mathrm{pH}$ of the solution was 2. The target compound was collected by filtration, washed thoroughly with $\mathrm{H}_{2} \mathrm{O}$, and dried under vacuum to afford 5 (1.01 g, yield 90.9\%). ${ }^{1} \mathrm{H}$ NMR (700 MHz, [D $\mathrm{D}_{6}$ DMSO): $\delta=13.10$ (brs, $3 \mathrm{H}), 8.26-8.20(\mathrm{~m}, 2 \mathrm{H}), 8.10-8.04(\mathrm{~m}, 4 \mathrm{H}), 7.96-7.88(\mathrm{~m}, 4 \mathrm{H}), 7.86-$ $7.80(\mathrm{~m}, 4 \mathrm{H}) ;{ }^{13} \mathrm{C}$ NMR $\left(175 \mathrm{MHz},\left[\mathrm{D}_{6}\right] \mathrm{DMSO}\right): \delta=167.20,167.17$, $167.07,143.63,143.32,140.78,140.34,138.85,138.64,132.52$, $130.25,130.12,130.08,129.84,129.52,127.77,127.64,127.41$, 127.30, 127.05, 126.86, 126.79; HRMS (El): $\mathrm{m} / \mathrm{z}$ : calcd for $\mathrm{C}_{27} \mathrm{H}_{18} \mathrm{O}_{6}$ : 438.1103; found: 438.1099 .

Scanning tunneling microscopy: A Nanoscope E STM (Digital Instruments) was used for all imaging. Highly oriented pyrolytic graphite (HOPG) (SPI-1 grade, Structure Probe Inc.) was used as a substrate for monolayer formation. A heptanoic acid solution of the desired molecule was made, of which $2 \mu \mathrm{L}$ was placed on freshly cleaved HOPG to obtain a self-assembled monolayer. Each solution was at or near saturation in heptanoic acid. STM tips were made from Pt/Ir (20\% Ir, 0.010 inch diameter, California Fine Wire) by mechanical cutting. Imaging was performed under ambient conditions and typical STM settings consist of $300 \mathrm{pA}$ current and 700-900 mV bias voltage (sample positive). All images are unfiltered. For a specific image, the cell constants may vary from the average due to the drift of the STM tip. Cell constants and symme- 
tries were determined by examining several images of both scan directions to account for this phenomenon.

Computational modeling: Molecular mechanics modeling of the 2D assemblies was performed in Materials Studio version 4.3 (Accelrys Software Inc.) using the assembled patterns and symmetry resolved in STM images with solvent omitted. Each lattice was geometry optimized in the Forcite module using the COMPASS force field ${ }^{[16]}$ without molecule or lattice constraints. This method has been shown to correctly describe the geometry and relative energy stability of 3D polymorphic arrangements in molecular crystals. ${ }^{[17]}$ Models of each lattice were built such that a layer of the model in the $a b$ plane represents the arrangement of molecules observed in the STM images for a given phase. The $c$ axis, which is the distance between monolayers, was set to $100 \AA$ for all models to minimize intermolecular interactions out of the $a b$ plane and this axis changed less than $3 \AA$ during optimization.

\section{Acknowledgements}

This imaging and modeling in this work was supported by the National Science Foundation (CHE-0957591). The synthesis of new materials was supported by the Department of Defense (DE-SC0004888).

Keywords: crystal engineering - hydrogen bonds - metalorganic frameworks • self-assembly • scanning tunneling microscopy

[1] a) K. E. Plass, A. L. Grzesiak, A. J. Matzger, Acc. Chem. Res. 2007, 40, $287-$ 293; b) A. I. Kitaigorodskii, Organic Chemical Crystallography, Consultants Bureau, New York, 1959.

[2] a) L. Kampschulte, M. Lackinger, A.-K. Maier, R. S. K. Kishore, S. Griessl, M. Schmittel, W. M. Heckl, J. Phys. Chem. B 2006, 110, 10829-10836; b) M. Lackinger, S. Griessl, W. M. Heckl, M. Hietschold, G. W. Flynn, Langmuir 2005, 21, 4984-4988; c) S. Griessl, M. Lackinger, M. Edelwirth, M. Hietschold, W. M. Heckl, Single Mol. 2002, 3, 25-31; d) M. Lackinger, S. Griessl L. Kampschulte, F. Jamitzky, W. M. Heckl, Small 2005, 1, 532-539; e) H. Zhou, H. Dang, J.-H. Yi, A. Nanci, A. Rochefort, J. D. Wuest, J. Am. Chem. Soc. 2007, 129, 13774-13775; f) L. Kampschulte, T. L. Werblowsky, R. S. K. Kishore, M. Schmittel, W. M. Heckl, M. Lackinger, J. Am. Chem. Soc. 2008, 130, 8502-8507; g) G.-J. Su, H.-M. Zhang, L.-J. Wan, C.-L. Bai, T. Wandlowski, J. Phys. Chem. B 2004, 108, $1931-1937$; h) Z. Li, B. Han, L. J. Wan, T. Wandlowski, Langmuir 2005, 21, 6915-6928; i) J. M. MaCLeod, O. Ivasenko, C. Fu, T. Taerum, F. Rosei, D. F. Perepichka, J. Am. Chem. Soc. 2009, 131, 16844-16850; j) N. T. N. Ha, T. G. Gopakumar, R. Gutzler, M. Lackinger, H. Tang, M. Hietschold, J. Phys. Chem. C 2010, 114, $3531-3536$

[3] J. K. Schnobrich, O. Lebel, K. A. Cychosz, A. Dailly, A. G. Wong-Foy, A. J. Matzger, J. Am. Chem. Soc. 2010, 132, 13941-13948.
[4] a) S. J. H. Griessl, M. Lackinger, F. Jamitzky, T. Markert, M. Hietschold W. M. Heckl, Langmuir 2004, 20, 9403-9407; b) J. Liu, X. Zhang, H.-J. Yan, D. Wang, J.-Y. Wang, J. Pei, L.-J. Wan, Langmuir 2010, 26, 81958200 ; c) S. J. H. Griessl, M. Lackinger, F. Jamitzky, T. Markert, M. Hietschold, W. M. Heckl, J. Phys. Chem. B 2004, 108, 11556- 11560.

[5] M. Lackinger, S. Griessl, T. Markert, F. Jamitzky, W. M. Heckl, J. Phys. Chem. B 2004, 108, 13652-13655.

[6] a) F. Tao, J. Goswami, S. L. Bernasek, J. Phys. Chem. B 2006, 110, 19562 $19569 ;$ b) K. G. Nath, O. Ivasenko, J. M. MacLeod, J. A. Miwa, J. D. Wuest, A. Nanci, D. F. Perepichka, F. Rosei, J. Phys. Chem. C 2007, 111, $16996-$ 17007.

[7] a) Z.-J. Lin, B. Xu, T.-F. Liu, M.-N. Cao, J. Lü, R. Cao, Eur. J. Inorg. Chem 2010, 2010, 3842-3849; b) C.-S. Lim, J. K. Schnobrich, A. G. Wong-Foy, A. J. Matzger, Inorg. Chem. 2010, 49, $5271-5275$; c) C.-C. Ji, J. Li, Y.-Z. Li, Z.-J. Guo, H.-G. Zheng, CrystEngComm 2011, 13, 459; d) L. Li, S. Wang, T. Chen, Z. Sun, J. Luo, M. Hong, Cryst. Growth Des. 2012, 12, 4109-4115; e) Y. Lu, W. Zhao, Y. Liu, B. Liu, X. Feng, J. Tan, X. Li, X. Yang, J. Solid State Chem. 2012, 192, 144-152; f) Z. Guo, H. Xu, S. Su, J. Cai, S. Dang, S. Xiang, G. Qian, H. Zhang, M. O'Keeffe, B. Chen, Chem. Commun. 2011, 47, 5551; g) Z. Zhang, L. Zhang, L. Wojtas, P. Nugent, M. Eddaoudi, M. J. Zaworotko, J. Am. Chem. Soc. 2012, 134, 924-927; h) W.-W. He, S.-L. Li, W.-L. Li, J.-S. Li, G.-S. Yang, S.-R. Zhang, Y.-Q. Lan, P. Shen, Z.-M. Su, J. Mater. Chem. A 2013, 1, 11111-11116; i) T. Liu, S. Wang, J. Lu, J. Dou, M. Niu, D. Li, J. Bai, CrystEngComm 2013, 15, 5476-5489; j) L. Li, S. Zhang, L. Han, Z. Sun, J. Luo, M. Hong, Cryst. Growth Des. 2013, 13, 106-110.

[8] A. G. Wong-Foy, O. Lebel, A. J. Matzger, J. Am. Chem. Soc. 2007, 129, $15740-15741$.

[9] S. S.-Y. Chui, S. M.-F. Lo, J. P. H. Charmant, A. G. Orpen, I. D. Williams, Science 1999, 283, 1148-1150.

[10] a) K. E. Plass, K. Kim, A. J. Matzger, J. Am. Chem. Soc. 2004, 126, 9042 9053 ; b) J. P. Rabe, S. Buchholz, L. Askadskaya, Synth. Met. 1993, 54 339-349; c) C. L. Claypool, F. Faglioni, W. A. Goddard, H. B. Gray, N. S. Lewis, R. A. Marcus, J. Phys. Chem. B 1997, 101, 5978-5995.

[11] L. Feng, Z. Chen, T. Liao, P. Li, Y. Jia, X. Liu, Y. Yang, Y. Zhou, Cryst Growth Des. 2009, 9, 1505-1510.

[12] a) E. Mena-Osteritz, Adv. Mater. 2002, 14, 609-616; b) T. Kirschbaum, R. Azumi, E. Mena-Osteritz, P. Bauerle, New J. Chem. 1999, 23, 241-250; c) P. Samorì, X. Yin, N. Tchebotareva, Z. Wang, T. Pakula, F. Jäckel, M. D. Watson, A. Venturini, K. Müllen, J. P. Rabe, J. Am. Chem. Soc. 2004, 126, 3567-3575; d) M. Fischer, G. Lieser, A. Rapp, I. Schnell, W. Mamdouh, S. De Feyter, F. C. De Schryver, S. Höger, J. Am. Chem. Soc. 2003, 125, $214-$ 222.

[13] S. L. Price, Chem. Soc. Rev. 2014, 43, 2098-2111.

[14] C. N. Morrison, S. Ahn, J. K. Schnobrich, A. J. Matzger, Langmuir 2011 27, $936-942$.

[15] J.-R. Li, H.-C. Zhou, Angew. Chem. Int. Ed. 2009, 48, 8465-8468; Angew. Chem. 2009, 121, 8617-8620.

[16] H. Sun, J. Phys. Chem. B 1998, 102, 7338-7364.

[17] K. R. Mitchell-Koch, A. J. Matzger, J. Pharm. Sci. 2008, 97, 2121-2129.

Received: December 3, 2014

Published online on March 3, 2015 